\title{
Pengembangan Sumber Daya Manusia di Industri Otomotif Melalui Institut Otomotif Indonesia
}

Mujiyono, Sonny Taufan

Program Studi Administrasi Bisnis Otomotif, Politeknik STMI

Jakarta, Indonesia

\begin{abstract}
Creating an organization or company, both in terms of form and purpose, is made based on a vision to fulfill human interests. In its implementation, the mission is managed by human resources. In addition, human resources are a central factor in an organization or company. So that the need for effective and efficient human resource management to achieve the company's goals optimally. This research is a case study using primary data collected from interviews and observations. In addition, it also uses supporting data, namely secondary data obtained from the results of previous studies and literature studies. This research aims to study and identify human resource development systems in the automotive industry by linking IOI's role in preparing competent human resources in the automotive industry in Indonesia. The results of the study show that the development and improvement of $\mathrm{HR}$ competencies in the automotive industry can be carried out by: (1) Competency-based education and training systems; (2) Organizing training with a 3 in 1 system; (3) Reskilling and Upskilling; and (4) participating in the PIDI 4.0 ecosystem. In addition, there is a need for good coordination and cooperation between IOI organizations and stakeholders such as academics, business, government, and society in order to be able to create competent human resources to advance the national automotive industry.
\end{abstract}

Keywords:

Development, Human Resources, Automotive Industry

\section{Corresponding Author:}

\section{Sonny Taufan}

Program Studi Administrasi Bisnis Otomotif, Politeknik STMI Jakarta

Email: sonny@stmi.ac.id

(C) The Author(s) 2021

DOI: https:/ / doi.org/ 10.36407/jmsab.v4i2.396

\section{(C) (2)}

CC BY: This license allows reusers to distribute, remix, adapt, and build upon the material in any medium or format, so long as attribution is given to the creator. The license allows for commercial use.
Research Paper

HR Management

Online: 18 Aug 2021

Jurnal Manajemen Strategi dan Aplikasi Bisnis, Vol 4, No. 2, 2021, pp. $401-408$ eISSN 2655-237X 


\section{PENDAHULUAN}

Industri manufakur merupakan salah satu sektor yang berperan penting dalam pertumbuhan ekonomi nasional, tidak hanya sebagai penyumbang terbesar terhadap PDB sebesar 20 persen, industri juga mampu memberikan kontribusi signifikan melalui setoran pajak yang mencapai Rp363,60 triliun atau 30 persen dari total penerimaan pajak pertahun 2018. Pencapaian ini meningkat 11,12 persen dibanding tahun sebelumnya. Selain itu, industri mampu menyumbang penerimaan cukai sebesar Rp159,7 triliun. (Humas, 2019). Terdapat 3 pilar utama untuk mendorong pertumbuhan industri nasional yaitu: investasi, teknologi, dan sumber daya manusia (SDM). Hakikatnya pencipatan suatu organisasi atau perusahaan baik bentuk dan tujuannya dibuat berdasarkan visi dalam memenuhi kepentingan manusia, dan dalam pelaksanaannya misi tersebut dikelola oleh sumber daya manusia.

Menurut (Kusdyah, 2011) Manajemen Sumber Daya Manusia berarti mengurus sumber daya manusia berdasarkan visi organisasi agar tujuan organisasi dapat dicapai secara optimum. Sumber daya manusia adalah faktor sentral dalam suatu organisasi. Apapun bentuk serta tujuannya, organisasi dibuat berdasarkan berbagai visi untuk kepentingan manusia dan dalam pelaksanaannya misi tersebut dikelola oleh manusia

Selanjutnya, sumber daya manusia juga merupakan faktor sentral dalam suatu organinasi atau perusahaan. Sehingga diperlukannya manajemen sumber daya manusia yang efektif dan efisien agar mampu mencapai tujuan perusahaan secara optimal. Selain itu, ketersediaan SDM Industri yang kompeten akan mendorong peningkatan produktivitas dan menjadikan industri lebih berdaya saing. Tujuan riset ini adalah untuk mengkaji dan mengindetifikasi sistem pengembangan sumber daya manusia pada industri otomotif. Serta dengan mengaitkan peran IOI dalam menyiapkan SDM yang kompeten pada industri otomotif yang ada di Indonesia. Manfaat dalam artikel jurnal lebih diarahkan ke ilmu pengetahuan atau solusi praktis dari persoalan yang ada dilapangan. Dan bagi masyarakat untuk menambah referensi dan masukan gambar an pengembangan sumber daya manusia di industri otomotif melalui Institut Otomotif Indonesia.

\section{METODE}

Riset ini merupakan studi kasus dengan menggunakan data primer yang dikumpulkan dari hasil wawancara dan observasi. Selain itu, juga menggunakan data pendukung yaitu data sekunder yang diperoleh dari hasil penelitian sebelumnya dan studi kepustakaan.

\section{HASIL DAN PEMBAHASAN}

\section{Pengembangan SDM Industri Otomotif Dan Peran IOI Dalam Menyiapkan SDM Industri Otomotif Yang Kompeten}

Institut Otomotif Indonesia (IOI) didirikan sebagai wadah untuk memajukan industri otomotif nasional, serta berperan sebagai think tank dalam pengembangan sumber daya manusia pada industi otomotif. Selain itu tujuan pengembangan SDM pada Industri Otomotif yaitu untuk menggerakkan dan mempercepat peningkatan daya saing pada industri manufaktur khususnya sektor industri. Sehingga hal ini memerlukan kordinasi dan kerjasama yang baik antara IOI dengan para pemangku kepentingan seperti akademi, bisnis, pemerintah dan masyarakat. 


\section{Mujiyono \& Sonny Taufan}

Development, Human Resources, Automotive Industry...

Terdapat 5 program pengembangan SDM pada Industri otomotif yang bisa dilakukan untuk meningkatkan kompetensi SDM dibidang otomotif, antara lain:

\section{Sistem Pendidikan Berbasis Kompetensi}

IOI memliki Kerjasama yang cukup kuat dengan Kementerian Perindustrian, dan salah satu keuntungannya adalah berkantor di Politeknik STMI Jakarta, yaitu Politeknik Kementerian Perindustrian yang memang dispesialisasikan untuk mendukung pembangunan SDM Industri bidang otomotif.

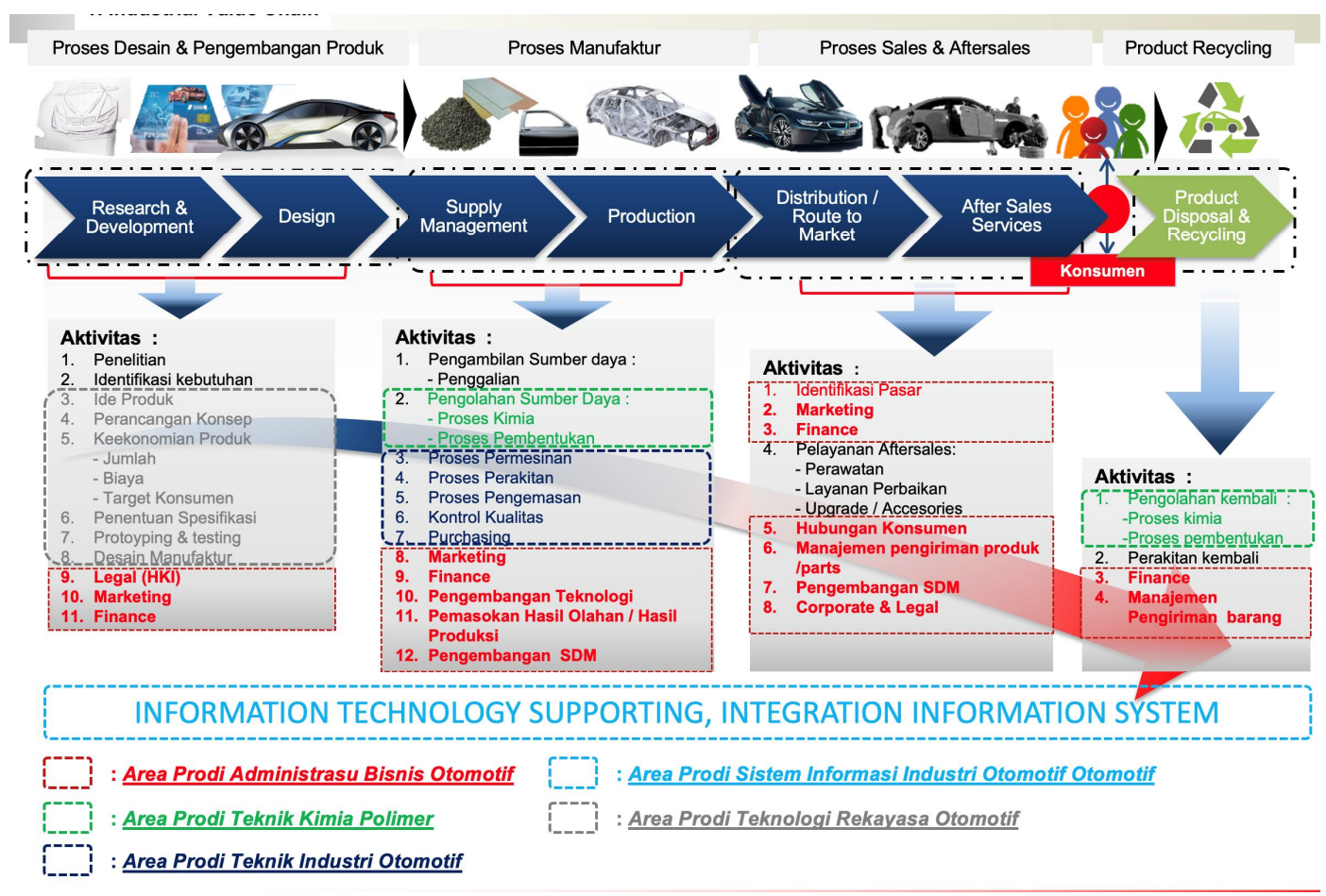

\section{Gambar 1.}

Kompentensi 5 Prodi Politeknik STMI Jakarta di Industri Otomotif Sumber: Politeknik STMI Jakarta

Dengan posisi ini, IOI bisa bekerjasama dengan STMI untuk memanfaatkan fasilitas dan memberdayakan SDM Politeknik STMI dalam mengembangkan sistem Pendidikan berbasis kompetensi, serta Bersama-sama menyelenggarakan program-program Pendidikan berbasis kompetensi. IOI dan Politeknik STMI Jakarta perlu berkolaborasi untuk pengembangan kurikulum, bahkan program studi yang diperlukan untuk mengantisipasi kebutuhan tenaga kerja inidustri otomotif sesuai kebutuhan kompetensi yang akan datang.

Selain itu, IOI dan Politeknik STMI Jakarta juga dapat bekerjasama menyelenggarakan program-program setara Diploma (baik Diploma I maupun Diploma II) yang bersifat on/ off dan dirancang khusus sesuai dengan kebutuhan dunia usaha industri dengan konsep dual system, yaitu Pendidikan teori di kelas lebih kurang 30-40\% dan sisanya pembelajaran melalui praktek kerja pada perusahaan industri sebesar 60-70\%.

\section{Pelatihan Berbasis Kompetensi}

Sistem Pendidikan dan pelatihan berbasis kompetensi diawali dengan penyusunan standar kompetensi kerja atau SKKNI yang disusun bersama oleh seluruh para pemangku kepentingan. 
SKKNI selanjutnya digunakan untuk penyusunan program dan modul pelatihan berbasis kompetensi hingga penyelenggaraan pelatihan dengan menggunakan sistem modular atau blok waktu. Selain itu, SKKNI juga menjadi acuan dalam pelaksanaan sertifikasi kompetensi, mulai dari pendirian LSP, penyiapan TUK dan asesor kompetensi, penyusunan materi, dan skema uji kompetensi hingga penyelenggaraan sertifikasi kompetensi.

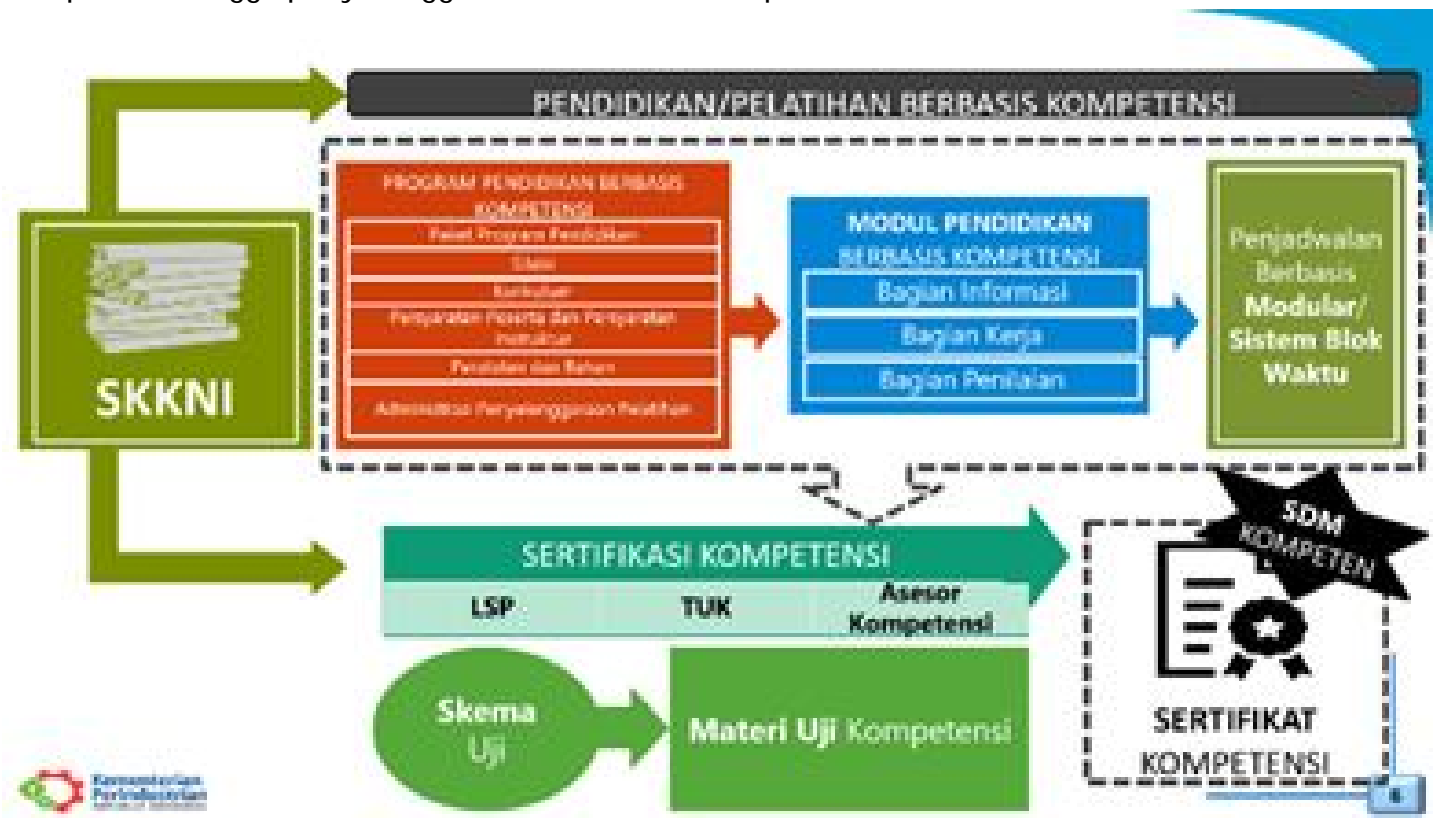

Gambar 2.

Skema Pendidikan/ Pelatihan Berbasis Kompetensi Sumber: Politeknik STMI Jakarta

Saat ini telah terdapat lima SKKNI bidang industri otomotif yang terdiri dari tiga SKKNI bidang manufaktur otomotif, yaitu: Pertama, SKKNI Bidang Komponen dan Aksesoris Kendaraan Bermotor; Kedua, SKKNI Bidang Kendaraan Bermotor Roda Empat atau Lebih, dan Ketiga, SKKNI bidang Karoseri. Sedangkan dua SKKNI Bidang Maintenance Otomotif yaitu, SKKNI Bidang Body Repair, dan SKKNI Bidang Service Otomotif. Dengan telah tersedianya SKKNI bidang industri otomotif tersebut, selanjutnya yang perlu dipersiapkan adalah ketersediaan Lembaga Sertifikasi Profesi (LSP) untuk menilai kesesuain kompetensi tenaga kerja atau calon tenaga kerja terhadap standar kompetensi yang ada.

Saat ini di bidang Maintenance Otomotif telah tersedia dua LSP, yaitu LSP Teknisi Otomotif (LSP TO) dan LSP Teknisi Otomotif Profesional (LSP TOP), namun belum tersedia LSP pada bidang manufaktur otomotif. Untuk itu IOI bersama asosiasi industri otomotif yang ada dapat bekerjasama mendorong dibentuknya LSP baru bidang manufaktur otomotif, atau mengembangkan skema sertifikasi untuk manufaktur otomotif pada LSP yang sudah tersedia. Peran penting lain yang bisa dijalankan oleh IOI adalah mempelopori terwujudnya rekognisi SKKNI dan sertifikasi kompetensi bidang otomotif secara regional dan global melalui Mutual Recognition Agreement (MRA). Dengan demikian, penyelenggaraan Pendidikan dan pelatihan berbasis kompetensi yang diselenggarakan tidak hanya untuk memenuhi kebutuhan tenaga kerja industri otomotif nasional tetapi juga dapat langsung untuk mensupply kebutuhan tenaga kerja industri otomotif di regional ASEAN bahkan global. 


\section{Penyelenggaraan Pelatihan Sistem 3 In 1}

Pelatihan sistem 3in1 (pelatihan-sertifikasi kompetensi-penempatan kerja) yang diselenggarakan oleh Kementerian Perindustrian telah dijadikan contoh skema pelatihan yang dinilai paling berhasil dalam memberikan dampak positif bagi masyarakat dan industri. Penyelenggaraan skema pelatihan sistem 3in1 memerlukan Kerjasama yang erat antara pemerintah, Lembaga pelatihan, masyarakat dan industri. IOI sebagai institusi independent yang berada ditengah para stakeholder serta terdiri dari perwakilan pemerintah, industri dan Lembaga Pendidikan mampu mengambil peran dengan mengkoordinasikan kebutuhan-kebutuhan tenaga kerja yang disesuaikan dengan kompetensi dan jenjang keahliannya. IOI juga dapat secara mandiri menyelenggarakan program pelatihan berbasis 3in1 tersebut dengan mengoptimalkan Kerjasama dengan para pelaku usaha otomotif.

Sebagai insentifnya sudah diterbitkan Peraturan Pemerintah (PP) Nomor 45 Tahun 2019 dan Peraturan Menteri Keuangan (PMK) Nomor 128 Tahun 2019 tentang insentif pajak super deduction hingga $200 \%$ bagi para pelaku usaha atau wajib pajak yang menyelenggarakan Pendidikan dan pelatihan vokasi. Selain itu dengan adanya wabah global pandemic COVID 19 yang terjadi sejak awal tahun 2020 ini bahkan sejak akhir 2019 secara global, banyak sektor industri yang terdampak, bahkan 60\% industri nasional dikategorikan hard hit/suffer, mengakibatkan banyaknya terjadi pemutusan kontrak dan PHK para tenaga kerja industri. Tahun 2021 sebagai tahun pemulihan ekonomi diyakini kebutuhan akan tenaga kerja akan kembali meningkat, sehingga kebutuhan akan pelatihan dan reskilling bagi korban PHK akan meningkat cukup signifikan.

\section{Re-skilling dan Up skilling}

Dengan diluncurkannya Making Indonesia 4.0 dan ditetapkannya industri otomotif sebagai salah satu dari 5 fokus sektor yang akan dikembangkan, merupakan sebuah tantangan sekaligus peluang bagi IOI untuk mengembangkan program-program reskilling dan upskilling bagi para tenaga kerja industri. Sebagaimana kajian Mc. Kinsey dalam Milward, Popescu, Michalikova, Musova, and Machova, V. (2019) bahwa penerapan Industri 4.0 akan membutuhkan reskilling dan upskilling mencapai 6-29 juta pekerjaan hingga 2030. IOI dapat mengambil peran dengan melakukan kajian kebutuhan reskilling dan upskilling bidang industri otomotif, sekaligus menyusun program pelatihan yang diperlukan untuk dapat menjadi acuan bagi pemerintah dalam menyelenggarakan program-program reskilling dan upskilling yang diperlukan.

\section{Partisipasi dalam Ekosistem PIDI 4.0}

Salah satu pilar dalam Pusat Inovasi dan Pengembangan SDM Industri 4.0 (PIDI 4.0) adalah showcase center, dimana pada tahap awal showcase yang dikembangkan adalah sektor otomotif dan sektor makanan dan minuman. Untuk penyelenggaraan showcase tersebut, diperlukan pelaku-pelaku usaha industri yang tergabung dalam ekosistem PIDI 4.0. Gambaran terkait dengan showcase yang akan ditampilkan dalam PIDI 4.0 adalah sebagai berikut: 


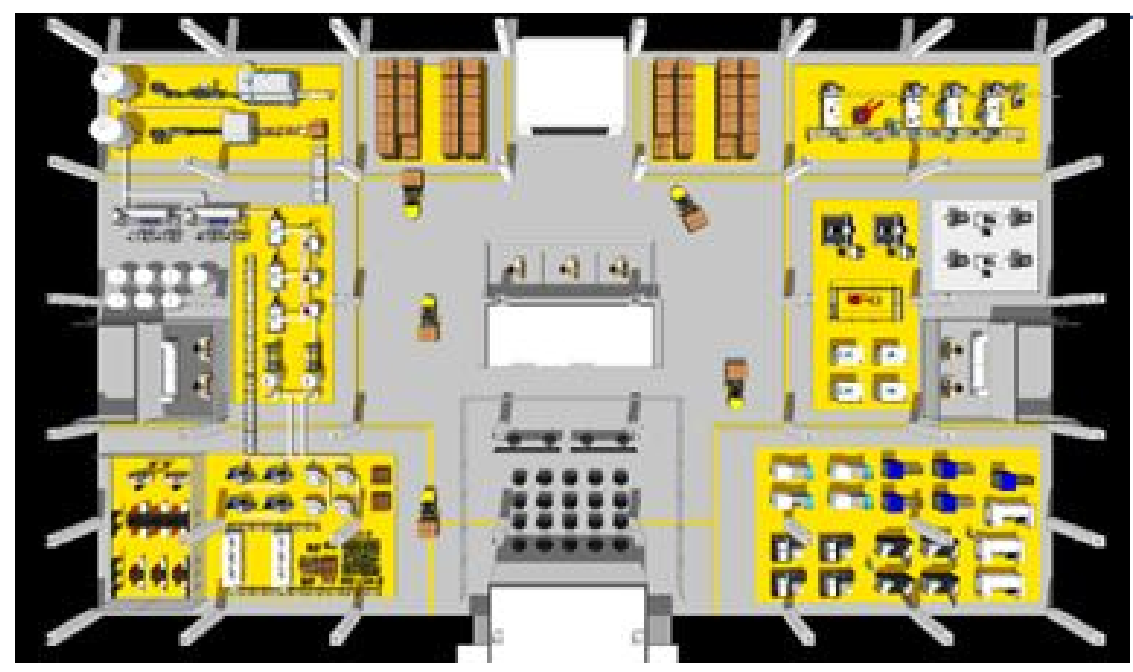

Gambar 3.

Showcase PIDI 4.0

Sumber: Badan Pengembangan Sumber Daya Manusia Industri

IOI sebagai wadah bagi para stakeholder Industri otomotif nasional perlu mengambil peran dalam menarik para pelaku usaha industri otomotif untuk bergabung dalam ekosistem PIDI dan memfasilitasi pengembangan IKM-IKM supplier, karena dari beberapa permasalahan (pain point) yang muncul dalam proses manufaktur industri otomotif diantaranya adalah terkait dengan supply chain. Secara garis besar dari hasil penilaian kesiapan transformasi industri 4.0, sektor otomotif dikategorikan berada pada kesiapan sedang untuk industri automaker yaitu industri otomotif roda 4 sebesar 2,71 dan sepeda motor 2,21 serta kesiapan awal untuk industri komponennya 1,73. Untuk menjembatani tingkat kesiapan antara automaker dan industri komponennya maka program implementasi industri 4.0 perlu dilakukan dengan membangun kolaborasi antara automaker dan industri komponen.

\section{KESIMPULAN DAN IMPLIKASI}

Berdasarkan keseluruhan susunan yang telah dipaparkan diatas, dapat disimpulkan bahwa bahwa pengembangan dan peningkatan kompetensi SDM pada industri otomotif dapat dilakukan dengan lima program pengembangan SDM, diantaranya: Pertama, Sistem pendidikan berbasis kompetensi; Kedua, Pelatihan berbasis kompetensi; Ketiga, Penyelenggaraan pelatihan dengan sistem 3 in1; Kempat, Reskilling dan Upskilling; dan Kelima, turut berpastisipsi dalam ekosistem PIDI 4.0. Selain itu diperlukannya kordinasi dan kerjasama yang baik antara organisasi IOI dengan para pemangku kepentingan seperti akademi, bisnis, pemerintah dan masyarakat agar mampu menciptakan SDM yang berkompeten untuk memajukan industri otomotif nasional. Serta mampu mensupply kebutuhan tenaga kerja industri otomotif untuk regional ASEAN bahkan global. Pengembangan sumber daya manusia di industri otomotif harus dilakukan koordinasi para pemangku kepentingan (ABG-C: Akademi, Bisnis, Pemerintah dan Masyarakat), tidak hanya melalui kegiatan kegiatan rapat koordinasi, tetapi lebih dalam bentuk aksi nyata yang bisa dijadikan acuan untuk program-program pengembangan SDM Industri Otomotif. 


\section{Mujiyono \& Sonny Taufan}

Development, Human Resources, Automotive Industry...

Terdapat sejumlah keterbatasan dalam penelitian ini yaitu studi kasus ini hanya membahas salah satu dari lima sektor manufaktur yang paling berpengaruh terhadap pertumbuhan ekonomi nasional, yaitu sektor industri otomotif dan kesimpulan penelitian hanya berlaku untuk industri otomotif saja. Sehingga riset berikutnya disarankan untuk melakukan penelitian lebih luas lagi mengenai pengembangan SDM di sektor manufaktur yang lainnya seperti sektor industri makanan dan minuman, tekstil, petrokimia, dan elektronika.

\section{Ucapan Terima Kasih}

Masukan dan Saran dari dua reviewer anonim sangat membantu untuk meningkatkan kualitas versi awal dari naskah ini. Terima kasih pula kami sampaikan kepada Pak Made Dana Tangkas, Presiden IOI yang telah melahirkan IOI di Indonesia.

\section{REFERENSI}

Arifin, Zl. (2018). Perencanaan Pengembangan Sumber Daya Manusia. Bandung: CV Manggu Lestari.

Kusdyah, R. I. (2011). Manajemen Sumber Daya Manusia. Yogyakarta: CV Andi Offset.

Milward, R., Popescu, G. H., Michalikova, K. F., Musova, Z., \& Machova, V. (2019). Sensing, smart, and sustainable technologies in Industry 4.0: Cyber-physical networks, machine data capturing systems, and digitized mass production. Economics, Management and Financial Markets, 14(3), 37-43.

\section{Competing Interests}

The authors declare that they have no competing interests

\section{Author(s) Detail}

Drs Mujiyono, MM adalah Dosen Senior di bidang Manajemen Sumber Daya Manusia di Program Studi Administrasi Bisnis Otomotif dan sampai saat ini masih diberikan amanah menjadi Tenaga Ahli Menteri Perindustrian Bidang Vokasi. Beliau pernah menjabat sebagai Tenaga Ahli Menteri Perindustrian bidang Pengembangan Pendidikan Vokasi tahun 2018-2019, Kepala Badan Pengembangan Sumber Daya Manusia Industri Tahun 2016-2018 sebelumnya beliau menjadi Kepala Pusat Pendidikan dan Pelatihan Kementerian Perindustrian Tahun 2012-2016. Minat penelitiannya termasuk manajemen sumber daya manusia dan perilaku organisasi. Penulis dapat dihubungi di email: mujiyono@stmi.ac.id

Sonny Taufan, SH., MH adalah Dosen di bidang Manajemen Sumber Daya Manusia, Hukum Ketenagakerjaan dan Hukum Bisnis di Program Studi Administrasi Bisnis Otomotif dan sekarang menjadi Pembantu Direktur I Bidang Akademik di Politeknik STMI Jakarta. Beliau menamatkan tingkat Sarjana di Fakultas Hukum Universitas Gadjah Mada dan tingkat Magister di Fakultas Hukum Bisnis Universitas Indonesia. Sekarang sedang melanjutkan program Doktor Ilmu Manajemen konsentrasi Manajemen SDM di UNJ mulai 2021. Minat penelitiannya termasuk manajemen sumber daya manusia dan hukum ketenagakerjaan dan hukum bisnis. Penulis dapat dihubungi di email: sonny@stmi.ac.id 
Jurnal Manajemen Strategi dan Aplikasi Bisnis, Volume 4, Nomor. 2, 2021. 401 - 408

This page intention to blank... 